\section{Tratamiento de recesiones gingivales con injerto de tejido conectivo subepitelial y técnica del sobre: reporte de caso}

\section{Treatment of gingival recessions with graft of subepithelial connective tissue and envelope technique: a case report}

\begin{abstract}
Resumen
El objetivo de esta presentación de caso es describir el uso de la técnica tipo sobre con injerto de tejido conectivo subepitelial en el tratamiento de dos recesiones gingivales clase I y II de Miller localizadas en 44 y 45 . Este caso es un paciente masculino de 50 ańos, que acudió al servicio de Periodoncia de la Clínica estomatológica "III Congreso del PCC", Matanzas, Cuba, por "cambio de posición de la encía en algunos dientes". Clínicamente existía exposición radicular en 44 y 45, sin presencia de bolsas periodontales, ni alteraciones radiográficas. Se diagnosticó recesión gingival localizada clase I de Miller en 44 y clase II en 45 . Se realizó injerto de tejido conectivo subepitelial y colgajo desplazado coronal tipo sobre. A los quince días, en zona receptora, existía edema, cobertura radicular completa del 45 y $2 \mathrm{~mm}$ de raíz expuesta en 44 . A los seis meses, mejoró condición periodontal del 44 . A los dos años las raíces expuestas estaban completamente cubiertas, con tejido gingival posicionado, ganancia de encía insertada y mimetismo de color entre sitio injertado y área adyacente. Se concluye que esta técnica logró resultados satisfactorios en el tratamiento de las recesiones gingivales de 44 y 45 .
\end{abstract}

Palabras clave: Recesión gingival; Injertos de tejido; Colgajos quirúrgicos (fuente: DeCS BIREME).

\begin{abstract}
The objective of this case presentation is to describe the use of the envelope technique with subepithelial connective tissue graft in the treatment of two Miller gingival recessions (class I and II) located at 44 and 45 . This case is a 50-year-old male patient, who went to the Periodontics service of the "III Congress of the PCC" Stomatology Clinic, Matanzas, Cuba, for "a change of the position of the gum in some teeth". Clinically, there was root exposure in 44 and 45 , without the presence of periodontal pockets or radiographic changes. Localized Miller class I gingival recession was diagnosed in 44 and Miller class II in 45. A subepithelial connective tissue graft and a coronal displaced envelope flap were performed. At fifteen days, in the receiving area, there was edema, complete root coverage of 45 and $2 \mathrm{~mm}$ of exposed root in 44 . At six months, periodontal condition of 44 has been improved. After two years, the exposed roots were completely
\end{abstract}

\section{Caso Clínico}

Rosario Cruz Morales 1,a,b, Dunia Caballero López ${ }^{1, a, b}$

1 Universidad de Ciencias Médicas "Juan Guiteras Gener", Matanzas, Cuba

a Cirujano Dentista.

${ }^{b}$ Doctor en Estomatología.

Correspondencia:

Rosario Cruz Morales: rosarioc.mtz@infomed.sld.cu Calle 140 edif. 18 apto 7 e/ 139 y 139 B. Rpto Reynold García Matanzas, Cuba.

ORCID: 0000-0002-5986-0502

\section{Coautora:}

Dunia Caballero López: duniacaballero.mtz@infomed.sld.cu ORCID: 0000-0001-8511-6077

Editor:

Donald Ramos-Perfecto

Universidad Nacional Mayor de San Marcos, Perú.

Conflicto de intereses: los autores declaran no tener conflictos de interés.

Fuente de financiamiento: Ministerio de Salud Pública (MINSAP).

Recibido: 28/10/19

Aceptado: $17 / 02 / 20$

Publicado: 09/05/20

(C) Los autores. Este artículo es publicado por la revista Odontología Sanmarquina de la Facultad de Odontología, Universidad Nacional Mayor de San Marcos. Este es un artículo de acceso abierto, distribuido bajo los términos de la licencia Creative Commons Atribucion - No Comercia_Compartir Igual 4.0 Internacional. (http://creativecommons.org/licenses/by-nc-sa/4.0/) que permite el uso no comercial, distribución y reproducción en cualquier medio, siempre que la obra original sea debidamente citada. 
covered, with positioned gingival tissue, inserted gingiva gain and color mimicry between grafted site and adjacent area. It is concluded that this technique achieved satisfactory results in the treatment of gingival recessions of 44 and 45 .

Keywords: Gingival recessions; Tissue graft; Surgical flap (source: MeSH NLM).

\section{Introducción}

La corrección de los problemas mucogingivales constituye uno de los objetivos principales de la cirugía plástica periodontal. Uno de estos problemas es la recesión gingival (RG) definida como el desplazamiento de los tejidos periodontales marginales a una posición apical a la línea amelocementaria, con la exposición de la superficie radicular. Puede localizarse en un diente, grupo de dientes o estar generalizada. Presenta una elevada prevalencia en el mundo, es multifactorial y puede asociarse a caries dental radicular, hiperestesia dentinal, abrasiones, compromisos a nivel estético y funcional según su grado de extensión, retención de biopelícula e inflamación ${ }^{1-3}$.

Miller ${ }^{4}$ en 1985 propuso una clasificación para determinar la probabilidad de cobertura radicular basándose en la extensión de las recesiones gingivales, así como en la presencia de tejidos interproximales. El clínico puede anticipar el grado de cobertura radicular al obtener la cobertura completa en las clases I y II, en las que existe recesión de los tejidos marginales sin pérdida de inserción periodontal en el área interdental; una cobertura parcial en la clase III, donde los tejidos marginales están retraídos hasta más allá de la unión mucogingival con pérdida de la inserción periodontal en la zona interdental o mala posición dentaria; y nula en la clase IV, cuando los tejidos marginales se extienden o van más allá de la unión mucogingival con avanzada pérdida de hueso o tejido blando en el área interdental o severa malposición dentaria.

Se han descrito numerosas técnicas para el cubrimiento de recesiones únicas y múltiples, con diferentes tipos y diseños de incisiones y mediante la utilización o no de injertos de tejido conectivo (ITC) ${ }^{5}$.

Edel ${ }^{6}$ en 1974, utilizó el ITC para ganar encía queratinizada y Langer y Langer ${ }^{7}$ lo usaron en 1985 para cubrir recesiones mediante un colgajo de avance coronal. En ese mismo ańo, Raetzke ${ }^{8}$ describe la técnica del «sobre», que consiste en la realización de un lecho receptor de espesor parcial sin levantar colgajo mediante incisiones divisorias por apical y proximal de la recesión e introducción del ITC dentro de ese sobre. Esta técnica tiene un porcentaje de éxito del $87 \%$ y en sus inicios surge para el tratamiento de recesiones gingivales únicas. Posteriormente Zucchelli y cols. ${ }^{9}$ la proponen con modificaciones, para el tratamiento de recesiones múltiples en pacientes con demandas estéticas. Se basaron en que las incisiones laterales descritas en la técnica de Langer y Langer ${ }^{7}$, y la tensión ejercida por las suturas sobre el colgajo, interrumpen la vascularización del área e interfieren negativamente en la cicatrización y en la estética.
El ITC junto con un colgajo de avance coronal obtiene los mejores resultados a corto y largo plazo en términos de cobertura de la raíz (CR) y aumento del tejido queratinizado, de ahí que muchos autores ${ }^{9-12}$ lo consideren el "gold estándar" de estos tratamientos.

Es importante considerar que además de la técnica a emplear, es imprescindible el correcto diagnóstico de la recesión gingival, la evaluación de las características clínicas de los tejidos adyacentes y la habilidad del profesional ${ }^{13}$.

Este reporte de caso tiene como objetivo describir el uso de la técnica del sobre con injerto de tejido conectivo subepitelial en el tratamiento de dos recesiones gingivales clase I y II de Miller localizadas en 44 y 45.

\section{Reporte del caso}

Paciente masculino, de 50 años de edad, que acude a consulta de Periodoncia de la Clínica estomatológica "III Congreso del PCC" (Partido Comunista de Cuba) de Matanzas, Cuba, remitido del nivel primario de atención por retracción gingival en 44 y 45. Al interrogatorio, negó antecedentes médicos personales y familiares de relevancia; refirió notar desde aproximadamente tres años "cambio de posición de la encía en dichos dientes" que avanzó en los últimos meses. Clínicamente existía exposición de las superficies radiculares por vestibular de 44 y 45 por migración apical del margen gingival sin alcanzar la línea mucogingival (LMG) en 44 y a nivel de la LMG del 45, y abrasión cervical en ambos. Ausencia clínica del 46 restituido por prótesis parcial removible metálica (Figura 1A).

Con calibrador Vernier marca Masters CE 1074 de origen alemán, se midieron las coronas clínicas de los dientes afectados desde el borde oclusal hasta el margen gingival ( $44=10,8 \mathrm{~mm} ; 45=10,5 \mathrm{~mm}$;). La RG se midió con sonda periodontal desde del borde cervical de la abrasión vestibular de 44 y 45 al cenit gingival de dichos dientes (RG del 44 y $45=3 \mathrm{~mm}$ ) (Figura 1). Encía adherida de $0,5 \mathrm{~mm}$ en 44 y 0 en 45 (medida con Pie de Rey desde el cenit gingival a la unión mucogingival).

Con sonda periodontal de Williams 3412 de origen alemán se determinó la profundidad del surco gingival de 44 y 45 , en ambos fue $1 \mathrm{~mm}$ interproximal y $0 \mathrm{~mm}$ en caras libres. No se apreció sangrado al sondaje, ni signos clínicos de inflamación, las papilas cubrían los espacios interdentales (Figura 1B y 1C). El paciente presentó higiene bucal adecuada con Índice de Análisis de Higiene Bucal de Love igual a $8 \%$.

Los dientes estaban firmes, libres de caries y obturaciones. Se indicó radiografía periapical que mostró integridad de las corticales óseas de 44 y 45, ausencia de pérdida ósea 
interproximal y de áreas radiolúcidas laterales y periapicales en los dientes con recesión.

Según las características clínico radiográficas se diagnosticó recesión gingival localizada clase I de Miller ${ }^{4}$ en el 44 y clase II en el 45, con lesión cervical no cariosa en ambos dientes y ausencia de encía adherida a nivel del 45. Se informó al paciente respecto al plan de tratamiento y se solicitó su autorización mediante formato escrito de consentimiento informado.

Procedimiento prequirúrgico. Se prescribieron exámenes complementarios: estudio hemático completo, recuento plaquetario y glicemia. Los valores estaban dentro del rango de normalidad.

Se realizó un injerto de tejido conectivo subepitelial cubierto por colgajo de espesor parcial tipo sobre desplazado coronalmente de 42 a 45 .

Acto quirúrgico. Antisepsia del campo operatorio con solución acuosa de acetato de clorhexidina al 0,2\% y anestesia del área quirúrgica con lidocaína al 2\% y epinefrina (1:80 000) con técnica infiltrativa tanto en sitio receptor como donante. Primero en sitio receptor en fondo del surco vestibular de 42 a 45 con refuerzo en base de papilas. En un segundo momento, en sitio donante (zona palatina entre 17 a 18). Con uńas de Moore marca Tekno de origen alemán, se rasparon las superficies radiculares expuestas de 44 y 45 y se alisaron con curetas periodontales tipo Gracey 5-6 (Masters) alemanas. No se usó acondicionador radicular.

Preparación del lecho receptor. Con hoja de bisturí Bard-Parker \# $15 \mathrm{C}\left(\right.$ Gaesca $\left.^{\mathrm{R}}\right)$ de origen alemán, se realizó una incisión intrasurcal del 42 a 45 conectada por una incisión horizontal sobre la base de las papilas ya desepitelizadas. Se disecó un colgajo de espesor parcial tipo bolsillo más allá de la línea mucogingival y se desinsertaron las fibras musculares para desplazar coronalmente el colgajo sin tensión.
Preparación del lecho donante y obtención del injerto: Se escogió la fibromucosa palatina de 17 a 18 para obtener el injerto con la técnica de una sola incisión descrita por Hürzeler (1999). El conjuntivo se separó del epitelio de la mucosa masticatoria del paladar y del periostio subyacente con bisturí y se extrajo el injerto de $14,7 \mathrm{~mm}$ de largo, 7,6 mm de alto y 1,7 $\mathrm{mm}$ de espesor, con pinza de disección sin dientes. Se colocó en una gasa estéril impregnada de suero fisiológico. Se suturó la herida lineal resultante con sutura continua (seda negra 3-0 no reabsorbible) (Figura 2A, 2B y 2C).

Fijación del injerto en sitio receptor. Se suturó al periostio del área receptora dentro del bolsillo, con puntos simples de sutura italiana de ácido poliglicólico 4-0 (Assupro ) reabsorbible y se cubrió con el colgajo reposicionado coronal, que se fijó alrededor del cuello de los dientes con sutura suspensoria seda negra 3-0 (Supramid Aragó) no reabsorbible de Barcelona España, con aguja de $3 / 8$ de círculo con reverso cortante. Se suturó de forma continua en el fondo del surco vestibular de 43 a 45 (Figura 2D y 2E).

Postoperatorio. Se prescribió analgésico oral en caso de dolor, Dipirona de $500 \mathrm{mg}$ (suministrada por China Meheco Corporation) 1 tableta cada 8 horas, Vitamina $\mathrm{C}$ de $500 \mathrm{mg}$, 1 tableta diaria por 15 días, mantener la cabeza elevada, sin acostarse en las primeras 6 horas. Ingerir líquido y alimentos blandos por 2 semanas, realizar colutorios de solución acuosa de clorhexidina al 0,2\% cada 12 horas a partir de las primeras 24 horas, por 15 días. Se orientó cepillado dentogingival en zonas no intervenidas. Ante cualquier malestar volver a consulta. Se citó a la semana para retirar sutura del paladar.

Evolución postoperatoria. A los siete días, se retiró sutura palatina y existía adecuada cicatrización de la zona donante; el área receptora permanecía cubierta por el apósito periodontal marca Quirucém de origen cubano. El paciente no presentó dolor, ni molestias postoperatorias mediatas.

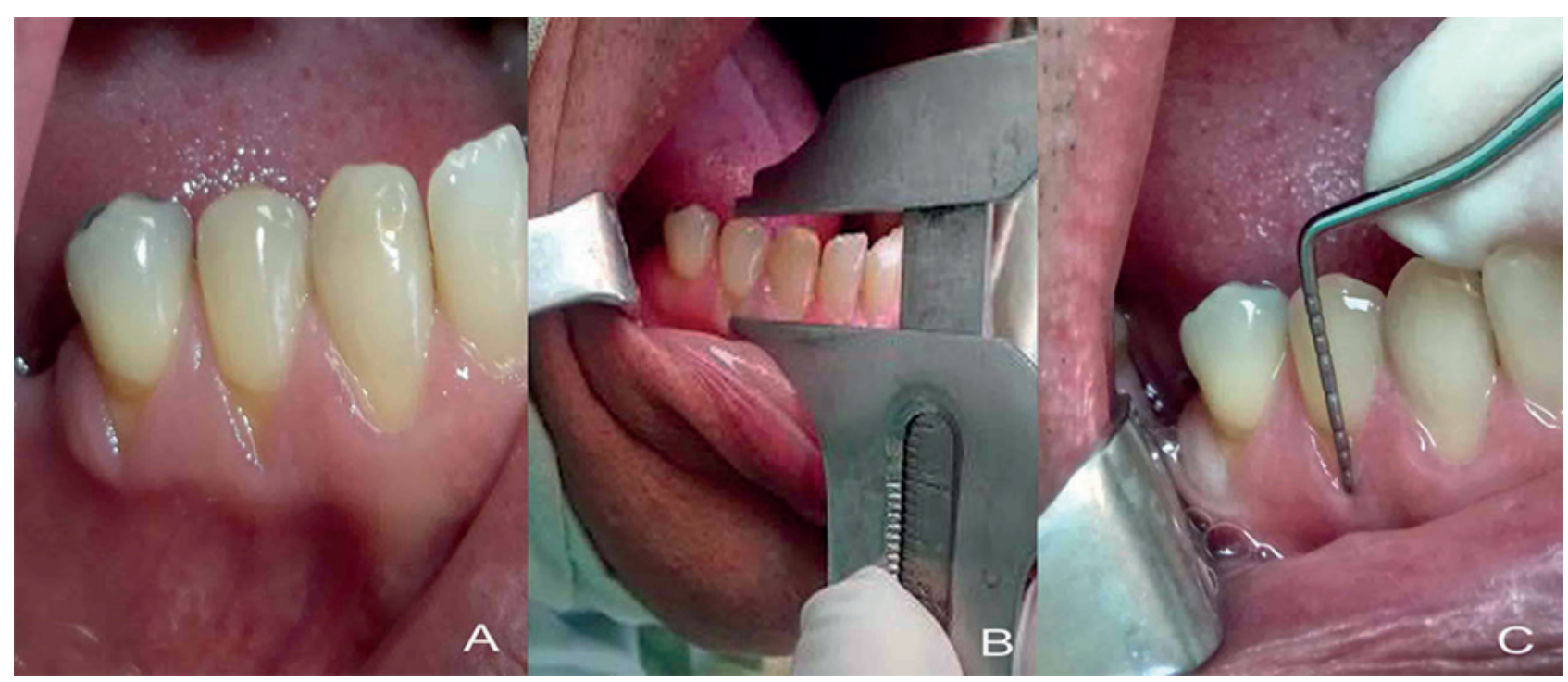

Figura 1. A. Recesiones gingivales de 44 y 45. B. Medición de corona clínica, recesiones. C. Sondaje del surco gingival 
Tras 15 días de cicatrización, se observó cobertura total de la raíz del 45, no así de la zona del 44 donde persistían $2 \mathrm{~mm}$ de raíz expuesta. Había ganancia de tejido queratinizado en área receptora y discreto edema (Figura 3A).

A los seis meses existía: mejoría del aspecto clínico gingival, ganancia de tejido queratinizado en 44 y 45, solo quedaba expuesta $1 \mathrm{~mm}$ de raíz en el 44 (Figura 3B).

A los dos años, el aspecto estético de la zona receptora era favorable, presentaba características clínicas de normalidad en relación con los tejidos circundantes en cuanto a color, textura y consistencia, había CR completa de 44 y 45, corona clínica del 44 de 7,8 mm, y del 45 de $7,5 \mathrm{~mm}$, la encía queratinizada medía $7 \mathrm{~mm}$, ambos aspectos verificados con pie de rey. Los tejidos periodontales presentaban inserción clínica adecuada, lo que fue comprobado con sonda periodontal (Figura 3C).

\section{Discusión}

Reportes recientes indican que el colgajo de avance coronal con injerto de tejido conectivo subepitelial, aumenta el aporte sanguíneo, protege al injerto, facilita su fijación e inmovilización, disminuye la contracción así como los problemas posoperatorios derivados de la pérdida de estabilidad del mismo y acorta el periodo de cicatrización ${ }^{6-12}$. Diferentes autores ${ }^{3,5,10-13}$ reportan que cuando se indica correctamente provee buenos resultados para la CR y existen factores que pueden influir en esto; entre ellos: los referentes al paciente, como una

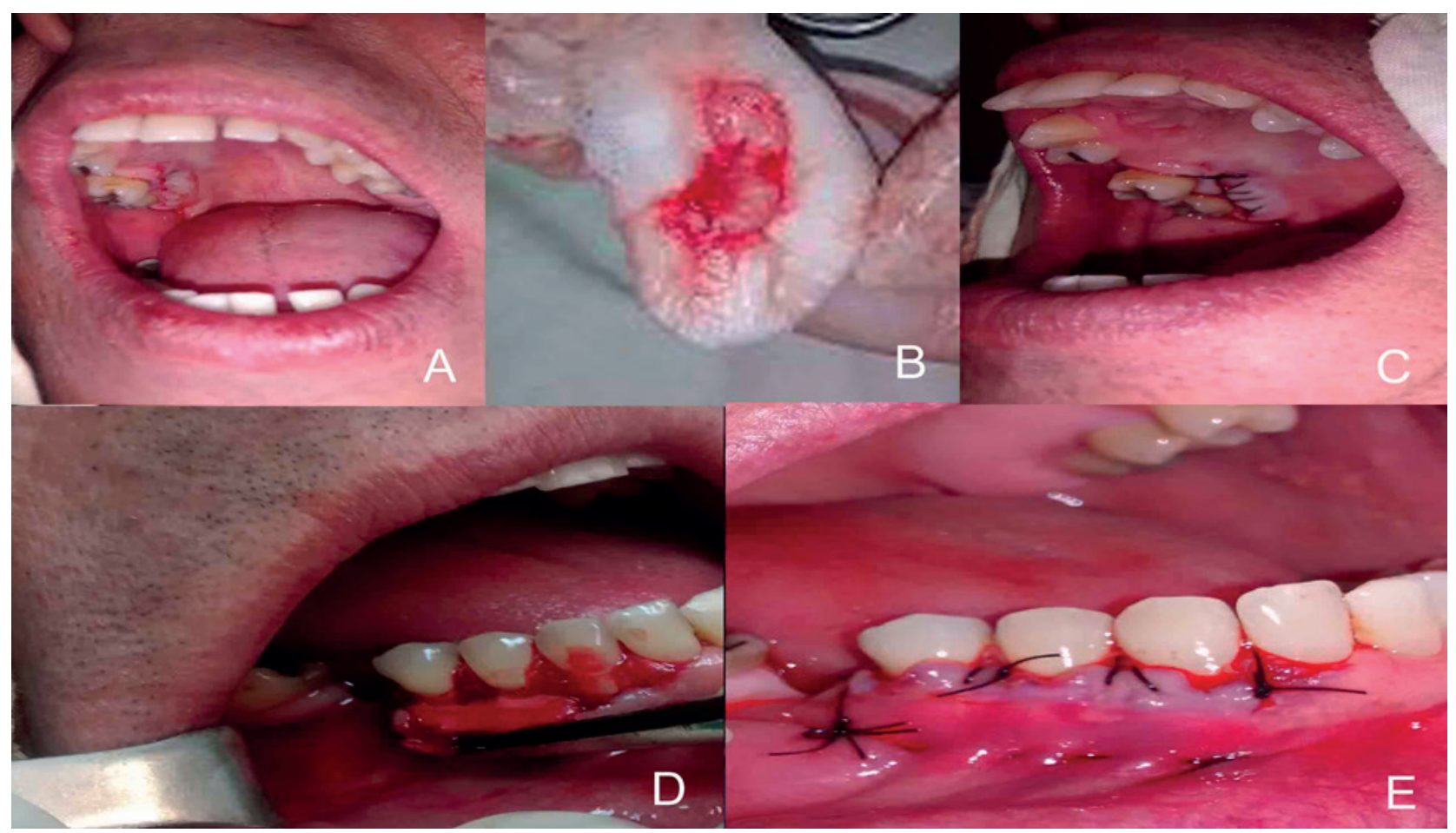

Figura 2. A. Incisión lineal para toma del injerto de zona palatina. B. Injerto de tejido conectivo. C. Sutura de zona donante. D. Fijación del injerto al periostio de zona receptora. E. Reposición coronal y sutura del colgajo tipo sobre

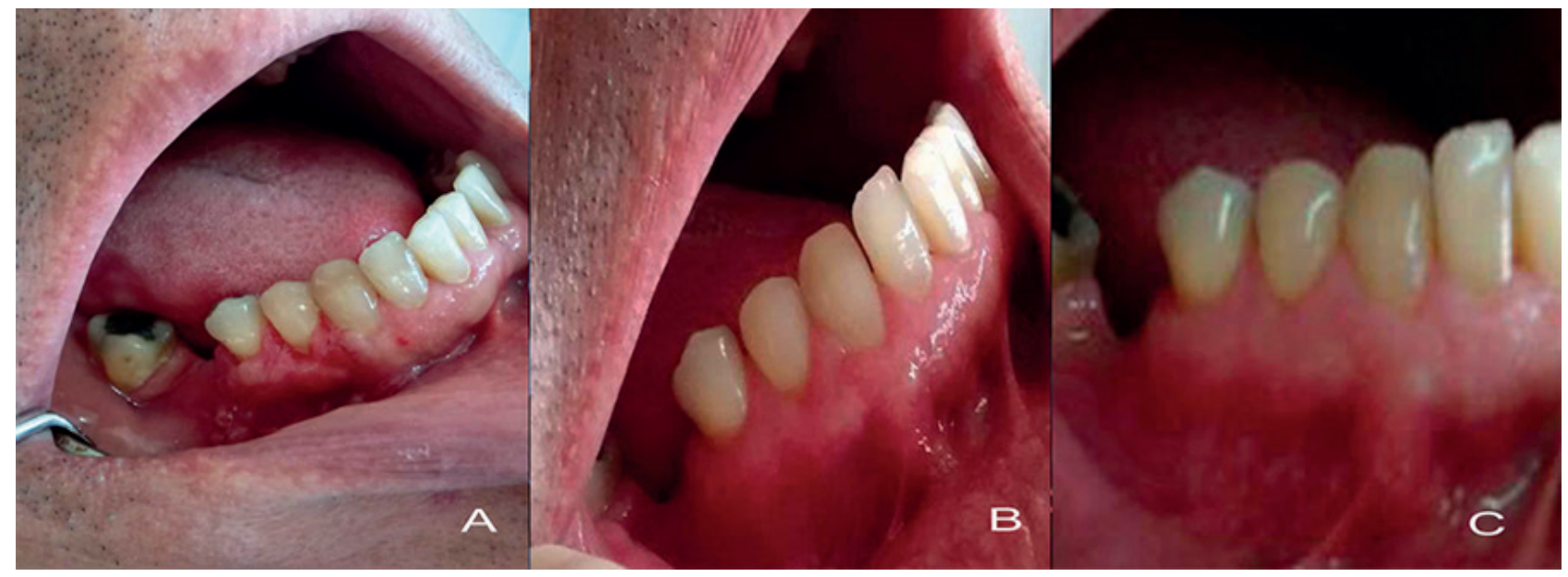

Figura 3. Evolución clínica del área receptora: A. A los 15 días, B. A los 6 meses y C. A los 2 años 
mala higiene bucal, una técnica de cepillado traumática y el hábito de fumar. Otros relacionados con el sitio receptor como el soporte periodontal interdental y otros factores vinculados a la técnica quirúrgica como: el espesor y tensión del colgajo y la localización postquirúrgica del margen gingival hacia coronal.

El caso clínico presentado mostraba higiene bucal adecuada, no era fumador y sus recesiones eran clase I y II de Miller, lo que justificó la realización de este tratamiento. También se tomó en consideración las conclusiones de una revisión sistemática y metaanálisis efectuada por Chambrone y Tatakis ${ }^{14}$, mencionando que los defectos provocados por recesiones no tratadas en individuos con buena higiene bucal, presentan alta probabilidad de progresar a largo plazo.

En este paciente no era pertinente realizar un colgajo desplazado coronal sin injerto, por el fino espesor del tejido gingival presente y la escasa cantidad de encía adherida en 44 y su ausencia en 45 . Por ello se decidió tomar tejido conectivo del paladar a nivel de 17 y 18 por presentar un área donante adecuada con suficiente espesor de fibromucosa.

A diferencia de la técnica de Raetzke ${ }^{8}$, en este caso, el sobre se extendió a los dientes adyacentes, para lograr mayor movilización coronal del colgajo. La ausencia de incisiones verticales liberatrices preservó la irrigación lateral, promovió un mínimo de trauma quirúrgico en el área receptora, proporcionó mejor cicatrización y eliminó la posibilidad de cicatriz en el tejido. El uso de una sola incisión para tomar el ITC, creó una mínima superficie de herida en la zona donante, aspectos también señalados por Zuchelli y colaboradores ${ }^{9,10}$.

El procedimiento utilizado es muy predecible y estable a largo plazo; provee mimetismo de color y aumenta el grosor gingival, por lo que previene la recidiva de la recesión y facilita el control de la biopelícula, aspectos referidos en la literatura por varios autores ${ }^{7-11}$.

Sin embargo, Escudero ${ }^{15}$ considera que el largo tiempo de preparación del lecho receptor y la posibilidad de perforación del colgajo durante su disección, son desventajas de esta técnica.

Por su parte, Dávila y cols. ${ }^{16}$ en su trabajo, comentan algunas limitaciones de los injertos libres de tejido conectivo. Entre ellas señalan que el paciente es intervenido en dos áreas distintas (zona donante y receptora), se necesita de un adecuado espesor de la mucosa donante y en algunas situaciones clínicas esta condición puede no presentarse, lo que reduce las posibilidades de cubrir áreas extensas en pacientes afectados por recesiones gingivales múltiples, por ello; en su estudio proponen los cultivos celulares y siembra sobre andamios de colágeno, como otra opción dentro de la amplia gama de posibilidades para el tratamiento de recesiones gingivales con resultados satisfactorios, estéticos y predecibles sin signos de rechazo inmunológico. Consideran que las técnicas de ingeniería tisular aportan un sustituto biológico de conectivo gingival como una alternativa de tratamiento aplicable en aquellos casos en los que las condiciones clínicas del paciente limiten el uso de técnicas convencionales como la empleada en este paciente donde si existía un adecuado espesor de tejido donante.

En este caso clínico, las abrasiones cervicales presentes en 44 y 45, no interfirieron en la CR de dichos dientes. Se sabe que la RG y las lesiones cervicales no cariosas suelen estar muy relacionadas porque comparten factores etiológicos y frecuentemente se deben tratar en conjunto para lograr resultados funcionales y estéticos satisfactorios. El uso de ITC subepitelial provee una alternativa biológica y definitiva que logra mejoría estética y crea una barrera de tejido que se opone a rompimientos futuros secundarios a inflamación asociada a irritantes locales o abrasión traumática por cepillado dental ${ }^{17}$.

Lindle, Miller y Nevins referidos por Dávila y cols. ${ }^{16}$ en su artículo, señalan que durante la fase de maduración en el período de cicatrización, las fibras colágenas que se forman dentro del nuevo tejido se orientan paralelas entre sí, y brindan mayor resistencia, lo que provoca contracción y posterior retracción del tejido injertado en comparación con su posición postoperatoria inicial.

Lo anteriormente expuesto no concuerda con las evidencias clínicas reportadas en este trabajo, en el que se produjo cobertura total de la superficie radicular del 44 al cabo de los 2 años de la intervención quirúrgica. Esto pudo deberse a algunos factores que pudieron estar presentes en este caso y que aparecen reportados en la literatura científica como: la movilización que experimentan los injertos en sentido coronal después de la fase de maduración, el tejido injertado presentaba un grosor de $1,7 \mathrm{~mm}$ y una altura similar al tamaño de la recesión y la presencia de un colgajo de espesor parcial con cobertura total del ITC lo que ofreció doble aporte sanguíneo y mayor índice de supervivencia $5,10-12$.

Los resultados clínicos logrados en el caso reportado respecto a CR, incremento del tejido queratinizado y aspecto estético, son comparables con los reportes de Rojo ${ }^{1}$, Sarduy ${ }^{11}$, Vargas ${ }^{18}$, Lino ${ }^{19}$, Tinajero ${ }^{20}$ y Jiménez $\mathrm{y} \operatorname{cols}^{21}$.

Se concluye que: la técnica empleada logró resultados satisfactorios en el tratamiento de las recesiones gingivales de 44 y 45 . Se recomienda realizar estudios prospectivos en un mayor número de pacientes que permitan medir a largo plazo, la cobertura radicular, el nivel de inserción gingival y la ganancia de encía queratinizada con el empleo de esta técnica quirúrgica.

\section{Referencias bibliográficas}

1. Rojo-Botello NR, Serrano-García SA, Vargas-Casillas AP. Injerto de tejido conjuntivo subepitelial. Caso clínico. Rev Esp Med Quir. 2016;21(1):31-38.

2. AAP connects. Glossary of periodontal terms. [Consultado el 23 de octubre del 2018]. Accesible en: https:// members.perio.org/libraries/glossary?ssopc $=1$

3. García-Rubio A, Bujaldón-Daza AL, Rodríguez-Archilla A. Recesión gingival. Diagnóstico y tratamiento. Av Periodon Implantol. 2015;27(1):19-24. 
4. Miller PD. Miller classification of marginal tissue recession revisited after 35 years. Compend Contin Educ Dent. 2018;39(8):514-520.

5. Robles Andrade MS. Predicción de la cobertura radicular completa: abordaje basado en evidencia. Rev. Mex. Periodontol. 2015;6(1):10-15.

6. Edel A. Clinical evaluation of the three connective tissue grafts used to increase the width of keratinized gingival. J Periodontol. 1974;1(4):185-96.

7. Langer B, Langer L. Subepithelial connective tissue graft technique for root coverage. J Periodontol. 1985;56(12):715-20.

8. Raezke P. Covering localized areas of root exposure employing the "envelope" technique. J Periodontol.1985;56(7):397-402.

9. Zuchelli G, Mounssif I, Mazzotti C. Coronally advanced flap without connective tissue graft for the treatment of multiple gingival recessions: a comparative short-and long-term controlled randomized clinical trial. J Clin Periodontol 2014;41(4):396-403.

10. Zucchelli G, Stefanini M, Ganz S, Mazzotti C, Mounssif I, Mazzotti M. Coronally advanced flap with different designs in the treatment of gingival recession: a comparative controlled randomized clinical trial. Int J Periodontics Restorative Dent. 2016;36(3):319-327.

11. Sarduy Bermúdez L, González Valdés Y, Barreto Fiu EE, Corrales Alvarez M. Tratamiento de recesiones periodontales con injerto libre y colgajo de reposición coronal más tejido conectivo. Medicent Electrón. 2018;22(3):218227.

12. Cairo F, Pagliaro U, Buti J, Baccini M, Graziani F, Tonelli $\mathrm{P}$ et al. Root coverage procedures improve patient aesthetics. A systematic review and Bayesian network meta-analysis. J Clin Periodontol. 2016;43(11):965-975. DOI: $10.1111 /$ jcpe. 12603 .

13. Bueno-Rossy LA. Cirugía Plástica Periodontal: reporte de un caso clínico. Odontoestomatol. 2016;18 (27):49-54.
14. Chambrone, L, Tatakis, DN. Long-Term Outcomes of Untreated Buccal Gingival Recessions: A Systematic Review and Meta-Analysis. J Periodontol. 2016;87(7):796808. DOI: $10.1902 /$ jop.2016.150625.

15. Escudero CN, Lorenzo VR, Bascones MA. Cirugía plástica periodontal de múltiples recesiones con la técnica de túnel modificada. Un caso clínico. JADA. 2007;2(2):421-426.

16. Dávila LB, Sosa JL, Padrón DK, Arteaga S, Olavez CD, Salmen HS, et al. Injerto gingival obtenido mediante ingeniería tisular. Rev Mex Periodontol. 2016;7(3):97103.

17. Juárez IA, Thiers SA, Lagos LA. Tratamiento de lesión cervical no cariosa y recesión gingival a través de colgajo posicionado coronalmente. Av Periodon Implantol. 2015;27(2):63- 66 .

18. Vargas CA, Mendoza EB, Borges YS. Comparación clínica del uso del colgajo de avance coronal e injerto de tejido conectivo subepitelial con o sin proteínas derivadas de la matriz del esmalte para la cobertura de recesiones gingivales. Caso clínico. Rev Odontol Mex. 2015;19(4):263272.

19. Lino AV, Hernández AY, Calixto AF, Galán TG. Tratamiento de recesiones gingivales múltiples con colgajo desplazado coronal. ORAL. 2018;19(59):1576-1580.

20. Tinajero AM, Pimentel LG, Changoluisa G, Tinajero CF. Coverage of Miller class I and II gingival recessions treated with subepithelial connective tissue graft, acellular dermal matrix, and enamel matrix proteins. Pilot study. Rev Odontol UNESP. 2016;45(2):78-84.

21. Jiménez F, Fernández M. Cobertura radicular con el procedimiento de colgajo de avance coronal en combinación con injerto de tejido conectivo autólogo: Revisión bibliográfica y reporte de caso. Odovtos-Int J Dental Sc. 2017;19(2):25-32. 